\title{
Derivation of Pipecolic Acid from L-Lysine by Familial Hyperlysinemics
}

\author{
N. C. Woody ${ }^{[13]}$ and M. B. Pupene \\ Department of Pediatrics, Tulane University School of Medicine, New Orleans, Louisiana, US.I
}

\begin{abstract}
Extract
Normal children and children with familial hyperlysinemia were given $\mathrm{L}-\left(\mathrm{U}-{ }^{14} \mathrm{C}\right)-\mathrm{ly}-$ sine by intramuscular injection. Labeled pipecolic acid and $N$ - $\alpha$-acetyllysine were found in the urines, indicating derivation of these substances from lysine. The percentage of administered radioactivity excreted as ${ }^{14} \mathrm{CO}_{2}$ and as urinary lysine varied markedly between controls and those with hyperlysinemia, but the percentage excreted in the urine in the form of various metabolites of lysine was about the same for controls (1.7-2.4) and those with hyperlysinemia (1.9-2.2). The proportion of these urinary lysine metabolites comprising pipecolic acid, homocitrulline, homoarginine, $N$ - $\epsilon$-acetyllysine and $N$ - $\alpha$-acetyllysine was two to seven times greater for children with hyperlysinemia than for controls. These findings suggest that these pathways for lysine degradation are being maximally utilized by patients with familial hyperlysinemia who cannot degrade lysine by way of the saccharopine pathway.
\end{abstract}

\section{Speculation}

L-Pipecolic acid is derived in humans, at least in part, from I-lysine. The availability of a pathway for lysine degradation by way of pipecolic acid may play some part in the fact that three of four children with hyperlysinemia in this family had no clear somatic expression of biochemical disorder.

\section{Introduction}

When pipecolic acid was found in the urine of young infants and of patients with familial hyperlysinemia, it was postulated that it derived from metabolism of L-lysine [8]. However, Grove and Henderson [3], in reviewing the earlier studies of Rothstein and Miller [4], demonstrated that rats derived more L-pipecolic acid from D-lysine than from L-lysine $(31.1 \%$ of $\mathrm{D}$-lysine being so converted as compared with $1.1 \%$ of L-lysine). This finding suggested that pipecolic acid excreted by normal humans $[2,8]$ might be derived from dietary D-lysine. In fact, the observation [2] that oral administration of L-lysine to normal subjects did not alter plasma pipecolate levels would support this idea.
To determine whether normal children and children with familial hyperlysinemia could convert L-lysine to pipecolatc, the excretion of labeled pipecolic acid and other lysine metabolites was measured follow-

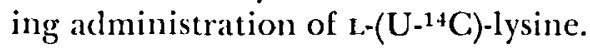

\section{Materials and Methods}

Two siblings with familial hyperlysinemia and two appropriate control children were given $25 \mu \mathrm{Ci}$ of $\mathrm{L}$ $\left(\mathrm{U}^{14} \mathrm{C}\right)$-lysine [10] by intramuscular injection [11]. This was prepared, sterilized, and tested for purity as previously described [7]. Urines were collected every $1.5 \mathrm{hr}$ for $12 \mathrm{hr}$; $10 \%$ thymol in isopropanol was added, and specimens were stored at $-50^{\circ}$ until ana- 
Table $I$. Percentage of administered radioactivity excreted during first $6 \mathrm{hr}$

\begin{tabular}{lccccc}
\hline & \multicolumn{2}{c}{ Control subjects } & & \multicolumn{2}{c}{$\begin{array}{c}\text { Patients with } \\
\text { hyperlysinemia }\end{array}$} \\
\cline { 2 - 3 } \cline { 5 - 6 } & A & B & & I & II \\
\hline${ }^{14} \mathrm{CO}_{2}$ & 7.4 & 9.1 & & 0.6 & 0.4 \\
Urine & & & & & \\
$\quad$ Lysine & 1.1 & 1.5 & & 14.4 & 1.8 \\
Lysine metabolites & 1.7 & 2.0 & & 1.6 & 1.5 \\
\hline
\end{tabular}

lyzed. Urine concentrates were separated by the technique of Spackman, Stein, and Moore $[5,8]$ into identifiable fractions by stream splitting. Four-fifths of the sample was diverted to a fraction collector and gathered in 2-ml portions. Each fraction was placed in a scintillation vial and dried on a $60^{\circ}$ hot plate in the hood. The dried residue was dissolved in $0.5 \mathrm{ml}$ of water. Twenty milliliters of scintillation fluid (a mixture of $67 \%$ toluene and $33 \%$ methylcellusolve with PPO $0.4 \%$ and POPOP $0.01 \%$ ) were added to each vial. Vials were counted in a scintillation counter [9] with a $50 \%$ efficiency for ${ }^{14} \mathrm{C}$. When ${ }^{14} \mathrm{C}$-glycine was serially diluted in water, processed as above, and counted, recoveries averaged $90 \%$ and were linear; when dissolved in the $0.2 \mathrm{~N}$ Na citrate buffers, $\mathrm{pH} 3.25$ and $\mathrm{pH} 4.25$, used in the amino acid analyzer, recoveries were, respectively, 86 and $64 \%$ and were also linear. No correction was made for this quenching effect. Methods for counting ${ }^{14} \mathrm{CO}_{2}$ and total lysine and lysine metabolites in urine have been previously described [7].

\section{Results}

Percentage of radioactivity excreted during the $6 \mathrm{hr}$ following administration of $\mathrm{L}-\left(\mathrm{U}-{ }^{14} \mathrm{C}\right)$-lysine is shown in Table I. This table restates, in somewliat more de- tail, data previously gathered in collaboration with others [7]. Of interest here is the fact that the percentage excreted in the urine as lysine metabolites is about the same for all the subjects although excretion of ${ }^{14} \mathrm{CO}_{2}$ and urinary lysine varied markedly between the controls and patients with hyperlysinemia.

Table II compares radioactivity measured in lysine and in the lysine metabolites in the urine. Values for homocitrulline, homoarginine, and $N_{-\epsilon}$-acetyllysine have been reported [8] and are included here for comparison with those found for pipecolic acid and $N_{-\alpha}-$ acetyllysine. The percentage of lysine metabolites excreted in the form of pipecolic acid, homocitrulline, homoarginine, $N_{-\epsilon}$-acetyllysine, and $N_{-\alpha}$-acetyllysine were two to seven times greater for patients with hyperlysinemia than for controls.

\section{Discussion and Summary}

Although control subjects and patients with hyperlysinemia both excreted about the same amount of the administered radioactivity in the form of lysine metabolites in the urine, the children with hyperlysinemia excreted a larger proportion of the label in the specific metabolites listed in Table II. This difference supports

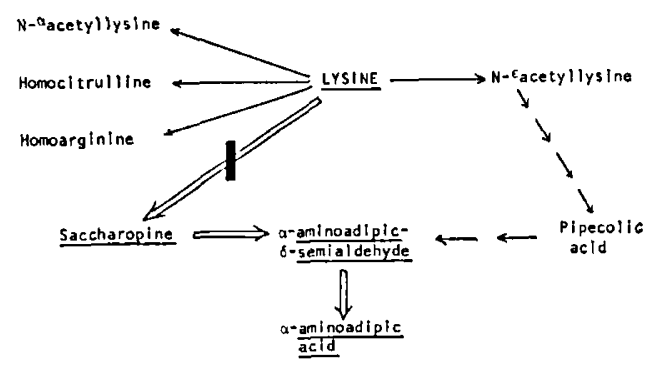

Fig. 1. Major and minor degradation pathways for lysine in man. Site of the block in familial hyperlysinemia is shown [1].

Table II. Lysine and lysine metabolites in urine ${ }^{1}$

\begin{tabular}{|c|c|c|c|c|c|c|c|c|c|c|c|}
\hline \multirow{3}{*}{ Compound } & \multicolumn{7}{|c|}{ Control subjects } & \multicolumn{4}{|c|}{ Patients with hyperlysinemia } \\
\hline & \multicolumn{4}{|c|}{ Patient A } & \multicolumn{3}{|c|}{ Patient B } & \multirow{2}{*}{\multicolumn{2}{|c|}{ I }} & \multirow{2}{*}{\multicolumn{2}{|c|}{ II }} \\
\hline & \multicolumn{2}{|c|}{ Preload $^{2}$} & \multicolumn{2}{|c|}{ Postload } & \multicolumn{2}{|c|}{ Preload } & Postload & & & & \\
\hline Lysine & & 3,588 & \multicolumn{2}{|r|}{4,635} & \multicolumn{2}{|r|}{5,106} & 4,458 & \multicolumn{2}{|c|}{28,883} & \multicolumn{2}{|r|}{10,117} \\
\hline Pipecolic acid & \multirow{2}{*}{$(2.3)^{3}$} & 92 & $(6.1)$ & 221 & $(4.7)$ & 207 & & $(21.8)$ & 540 & $(10.6)$ & 392 \\
\hline Homocitrulline & & 0 & $(2.7)$ & 100 & & 0 & $(2.4)$ & $(15.5)$ & 381 & $(16.2)$ & 600 \\
\hline Homoarginine & \multirow{4}{*}{$(5.8)$} & 0 & $(0.8)$ & 28 & & 0 & $(1.1)$ & $(4.5)$ & 112 & $(3.0)$ & 110 \\
\hline$N$-t-acetyllysine & & 0 & $(2.7)$ & 97 & $(3.4)$ & 149 & $(6.8)$ & $(13.2)$ & 324 & $(9.0)$ & 334 \\
\hline$N$ - $\alpha$-acetyllysine & & 233 & $(4.9)$ & 180 & $(3.8)$ & 167 & $(6.5)$ & $(15.5)$ & 381 & $(19.3)$ & 714 \\
\hline Total lysine metabolites & & 4,002 & & 3,640 & & 4,375 & 3,640 & & 2,463 & & 3,698 \\
\hline
\end{tabular}

1 Values are $\mathrm{cpm} / \mathrm{mg}$ of urinary creatinine.

${ }^{2}$ With $150 \mathrm{mg} / \mathrm{kg}$ of $\mathrm{L}$-lysine orally.

${ }^{3}$ Figures in parentheses are percentage of total lysine metabolites. 
the observation of Dancis $e t$ al. [1] that normal children have a metabolic pathway, through the formation of saccharopine, which is open to them for the metabolism of lysine and which is not available to children presenting with familial hyperlysinemia. The latter are utilizing alternate pathways via the substances shown in Figure 1. The availability of these alternate paths, especially that by way of pipecolic acid, may explain the fact that three of the four children with hyperlysinemia in this family had normal growth and were not mentally affected by their metabolic clisease [6].

Demonstration of radioactivity in urinary pipecolate and $N$ - $\alpha$-acetyllysine of children and patients with hyperlysinemia following parenteral administration of $L$ $\left(\mathrm{U}-{ }^{14} \mathrm{C}\right)$-lysine indicates that these substances are derived from L-lysine in the human.

\section{References and Notes}

1. Dancis, J., Hutzler, J., Cox, R. P., And Woody, N. C.: Familial hyperlysinemia with lysine ketoglutarate reluctase insufficiency. J. Clin. Invest., f8: 1447 (1969).

2. Gatfield, P. D., Taller, E., Hinton, G. G., Wallace, A. C., Aboelnour, G. M., ANd Haust, M. D.: Hyperpipecolatemia:
A new metabolic disorder associated with neuropathy and hepatomegaly. Can. Med. Ass. J., 99: 1215 (1968).

3. Grove, J., ANd Henderson, L. M.: The metabolism of b- and 1.-lysine in the intact rat, perfused liver and liver mitochondria. Biochim. Biophys. Acta, 165: 113 (1968).

4. Rothistein,, M., and Miller, L. L.: The conversion of lysine to pipecolic acid in the rat. J. Biol. Chem., 211: 851 (1954).

5. Spackman, D. H., Strin, W. H., aND Moore, S.: Automatic recording apparatus for use in chromatography of amino acids. Anal. Chem., 30: 119 (1958).

6. Woony, N. C.: Unpublished data.

7. WOODY, N. G.: Hutzler, J., AND DANCts, J.: Further studies of hyperlysinemia. Amer. J. Dis. Child., 112: 577 (1966).

8. Woony, N. C., ANd Pupene, M. B.: Excretion of pipecolic acid by infants and by patients with hyperlysinemia. Pediat. Res., t: $89(1970)$.

9. Nuclear Chicago, model 720, Des Plaines, Ill.

10. Chemtrac, Cambridge, Mass.

11. Informed consent was obtained by methods approved by the Tulane Medical School's Committec on the Use of Human Subjects in Research

12. Supported by Public Health Service Research Grant no. HD02920

13. Requests for reprints should be addressed to: N. C. WoopY, M.D., Department of Pediatrics, Tulane University School of Medicine, 1430 Tulanc Avenue, New Orleans, La. 70112 (USA).

14. Accepted for publicaton November 25, 1970. 